\title{
Continental Scale Mapping of Tidal Flats across East Asia Using the Landsat Archive
}

\author{
Nicholas J. Murray ${ }^{1,2, *}$, Stuart R. Phinn ${ }^{3}$, Robert S. Clemens ${ }^{1}$, Chris M. Roelfsema ${ }^{3}$ and \\ Richard A. Fuller ${ }^{1,2}$
}

1 School of Biological Sciences, The University of Queensland, St Lucia, QLD 4072, Australia; E-Mails: r.clemens@uq.edu.au (R.S.C.); r.a.fuller@dunelm.org.uk (R.A.F.)

2 CSIRO Climate Adaptation Flagship and CSIRO Ecosystem Sciences, 41 Boggo Road, Dutton Park, QLD 4102, Australia

3 Centre for Spatial Environmental Research, School of Geography, Planning and Environmental Management, The University of Queensland, St Lucia, QLD 4072, Australia; E-Mails: s.phinn@uq.edu.au (S.R.P.); c.roelfsema@uq.edu.au (C.M.R.)

* Author to whom correspondence should be addressed; E-Mail: nick.murray@uq.edu.au; Tel.: +61-7-3365-2527.

Received: 27 August 2012 in revised form: 2 November 2012 / Accepted: 2 November 2012 / Published: 9 November 2012

\begin{abstract}
Tidal flats provide habitat for biodiversity, protection from storm surges and sea level rise, and a range of other ecosystem services. However, no simple method exists for mapping tidal flats over large $(>1,000 \mathrm{~km})$ extents, and consequently their global status and distribution remain poorly understood. Existing mapping methods are restricted to small areas with known tidal regimes because tidal flats are only fully exposed for a brief period around low tide. Here we present a method for mapping tidal flats over very large areas and demonstrate its utility by mapping the tidal flats of China, the Democratic People's Republic of Korea and the Republic of Korea. We (i) generated tide height predictions at the acquisition time of all Landsat Archive images of our study area using a validated regional tide model, (ii) selected suitable images acquired in the upper and lower $10 \%$ of the tidal range, (iii) converted high and low tide images to a land and water class image derived from the Normalized Differenced Water Index (NDWI) and, (iv) subtracted the high tide classified image from the low tide classified image, resulting in delineation of the tidal flat. Using this method, we mapped the tidal flats for $86.8 \%$ of the study area coastline $(13,800 \mathrm{~km})$. A confusion matrix for error assessment indicated an accuracy of $>85 \%$ for the resulting tidal flat map. Our method enables coastal morphology to be
\end{abstract}


mapped and monitored at continental scales, providing critical data to inform coastal adaptation measures for sea level rise, for monitoring coastal habitat loss and for developing ecosystem-based coastal conservation measures.

Keywords: mudflat; intertidal flat; coastal wetland; delta; coastline; land cover; salt marsh; Normalized Differenced Water Index (NDWI)

\section{Introduction}

Tidal flats, the area between marine and terrestrial environments, are critically important for supporting biodiversity and providing coastal ecosystem services (e.g., storm protection) [1,2]. Yet, despite an abundance of remote sensing projects that have focused on coastal areas [3-5], there is no global estimate of the extent of tidal flats and present knowledge of their overall distribution remains limited. This is primarily due to a deficiency of tidal flat mapping techniques suitable for use over very large areas. Due to human impacts and a range of other threats, tidal flats are rapidly changing and reliable knowledge of their status is urgently required [6,7].

Mapping tidal flats accurately is difficult because they are only exposed fully for a brief period at low tide, requiring precise timing of the acquisition of remotely sensed data. Specific applications of high precision mapping of tidal flats have been achieved in some countries using Light Detection and Ranging (LIDAR) and Synthetic Aperture Radar (SAR) from aircraft [4,8]. However, these methods are limited for application over continental scales because of rapidly changing tidal conditions and the high cost of airborne acquisitions [3,9].

Over larger areas, satellite sensors such as the Landsat Thematic Mapper (TM), Enhanced Thematic Mapper (ETM+), MODIS and SPOT are regularly used to map the boundary between a water body and the exposed terrestrial surface, known as the waterline. A range of methods to establish the location of waterline have been developed, including manual digitization [10,11], edge detection [12], density slicing $[9,13]$ and multi-band classification [14]. By delineating the waterline at known tide heights, digital elevation models for the intertidal zone can be developed and tidal flats mapped to high accuracy [9]. However, if the aim is to map the extent of tidal flats, these methods are only suitable for areas where there is tide height information for the precise time of data capture. Furthermore, by focusing only on the low-tide waterline they do not account for the location of the high-tide waterline, which is fundamental in determining the area of tidal flat. This is particularly important for continental scale mapping, where information on the location of the high-tide waterline is not readily available. Thus, to determine the distribution and extent of tidal flats at continental scales, mapping methods must be developed that can manage (a) the scarcity of observed tide height data and (b) variation in the position of the high-tide waterline.

Here we address this deficiency by developing a new methodology for mapping tidal flats suitable for application over continental or global scales. We use large-scale, freely available Landsat Archive imagery and tide predictions from validated regional tide models to map areas where there is no prior information on tide heights available. By considering only two classes (tidal flat and other) and incorporating information on high-tide waterlines, tidal flats are mapped rapidly and accurately at a 
continental scale. We demonstrate this method over $\sim 16,000 \mathrm{~km}$ of coastal East Asia, from southern China to the Republic of Korea, a region with some of the largest tidal flats globally [1].

\section{Methods}

Our study area comprised the coastline from the Vietnam-China border $\left(21^{\circ} 32^{\prime} \mathrm{N}, 108^{\circ} 1^{\prime} \mathrm{E}\right)$ to the eastern Democratic People's Republic of Korea-Republic of Korea border ( $\left.38^{\circ} 36^{\prime} \mathrm{N}, 128^{\circ} 21^{\prime} \mathrm{E}\right)$.

\subsection{Satellite Sensor and Image Selection}

Metadata for all Landsat TM and ETM+ images available for the study area since 2000 were obtained (13,125 images) using the USGS Earth Explorer [15], which contained information on the geographic location, cloud cover and acquisition time and date. Knowledge of tide height is critical for mapping the extent of tidal flats, so we determined the tide height at image acquisition for all available images by generating tide predictions for a point $5 \mathrm{~km}$ from the coastline and nearest to the coastline mid-point of each image, allowing selection of images obtained at known tide heights (Figure 1). We used the Tide Model Driver and the Oregon State University Tidal Inversion Software to operate the China Seas tide model, which is a regionally validated tide model with an RMS misfit of $<5 \mathrm{~cm}$ [16-18].

Figure 1. High resolution example of tidal flat exposure between high tide (left) and low tide (right) Landsat TM images (bands 4, 5, 3) in the Democratic People's Republic of Korea. The tidal flat, which appears in the low tide image as a light band around the coastline, is not present in the high tide image. Other changes in the images are due to image acquisition occurring in different seasons.
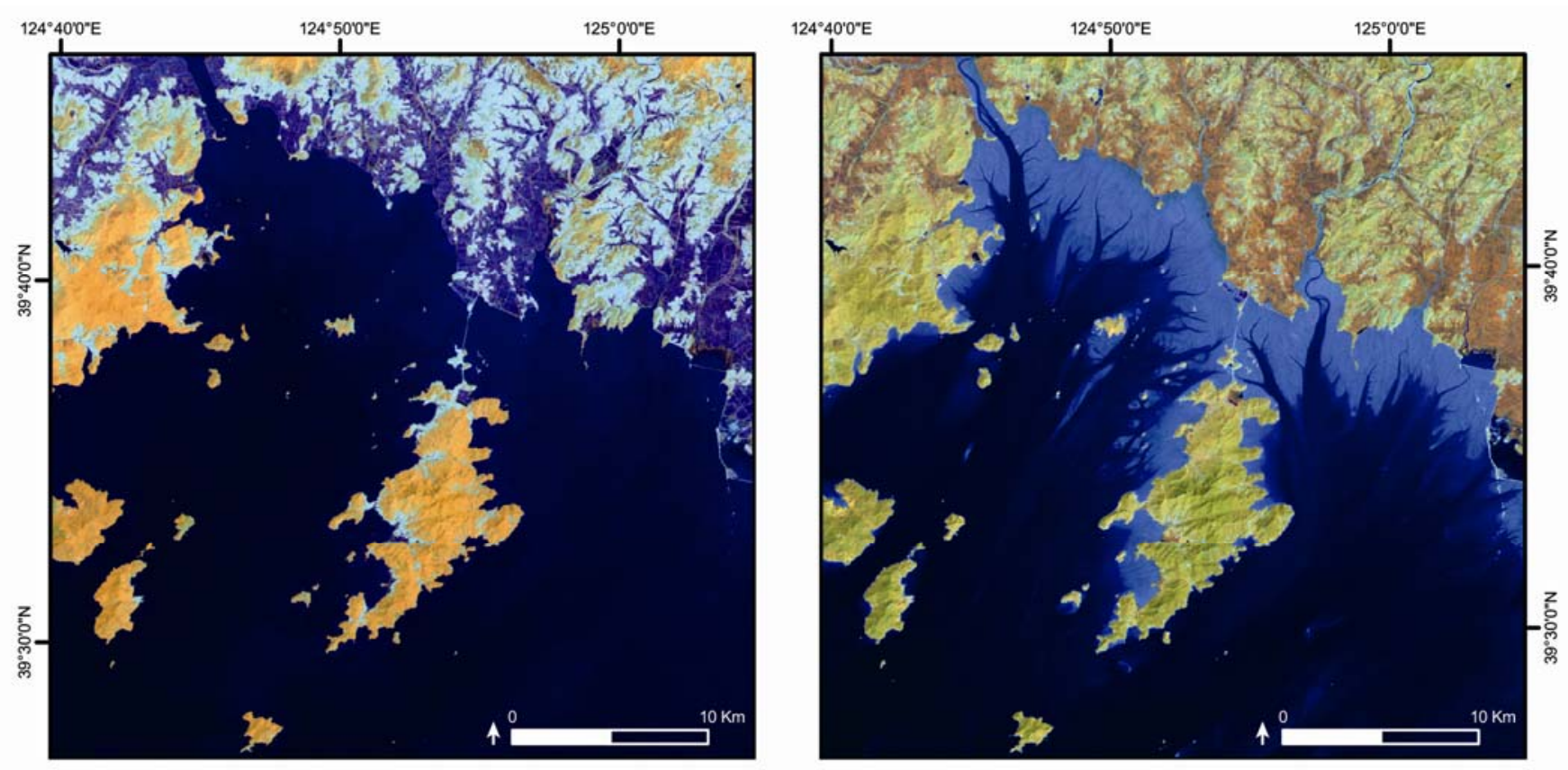

We obtained all images in the upper (high tide) and lower (low tide) $10 \%$ of the tidal range with a cloud coverage of $<30 \%$ (1,040 images). From this image set, the final low-tide and high-tide images were selected according to the following selection criteria; (i) obtain the highest and lowest tide heights possible, (ii) minimize the period of time elapsed between capture of the high and low tide 
images, (iii) minimize coastal cloud cover and, (iv) use the most recent imagery available. The final set, covering the entire coastline of China and the Korean Peninsula, contained 78 images over 39 path/rows with a mean time difference between high and low tide images of 664 days $(\sigma=532$ days).

\subsection{Image Pre-processing}

The final image set was pre-processed to at-surface reflectance by converting digital number values to at-sensor reflectance and then applying a dark pixel subtraction to account for atmospheric attenuation [19-21]. Georectification was not required as all images were processed to USGS level 1 terrain-corrected products (L1T), which was determined as an acceptable level of spatial accuracy for the aims of the study [22].

\subsection{Tidal Flat Delineation}

To map the tidal flat, which we defined as the area inundated between the low and high tide waterline, we developed a 2 phase process centered on differencing high and low tide TM and ETM+ images (Figure 2). The method was implemented in ArcGIS 10.0 using the Python programming language.

Figure 2. The image differencing method for mapping tidal flats. A regional tide model is used to identify images acquired at high and low tide. Mapping of tidal flats is then achieved by creating a land/water classified image from the Normalized Differenced Water Index (NDWI), and subtracting the high tide classified image from the low tide classified image, resulting in delineation of the tidal flat (shown in red).

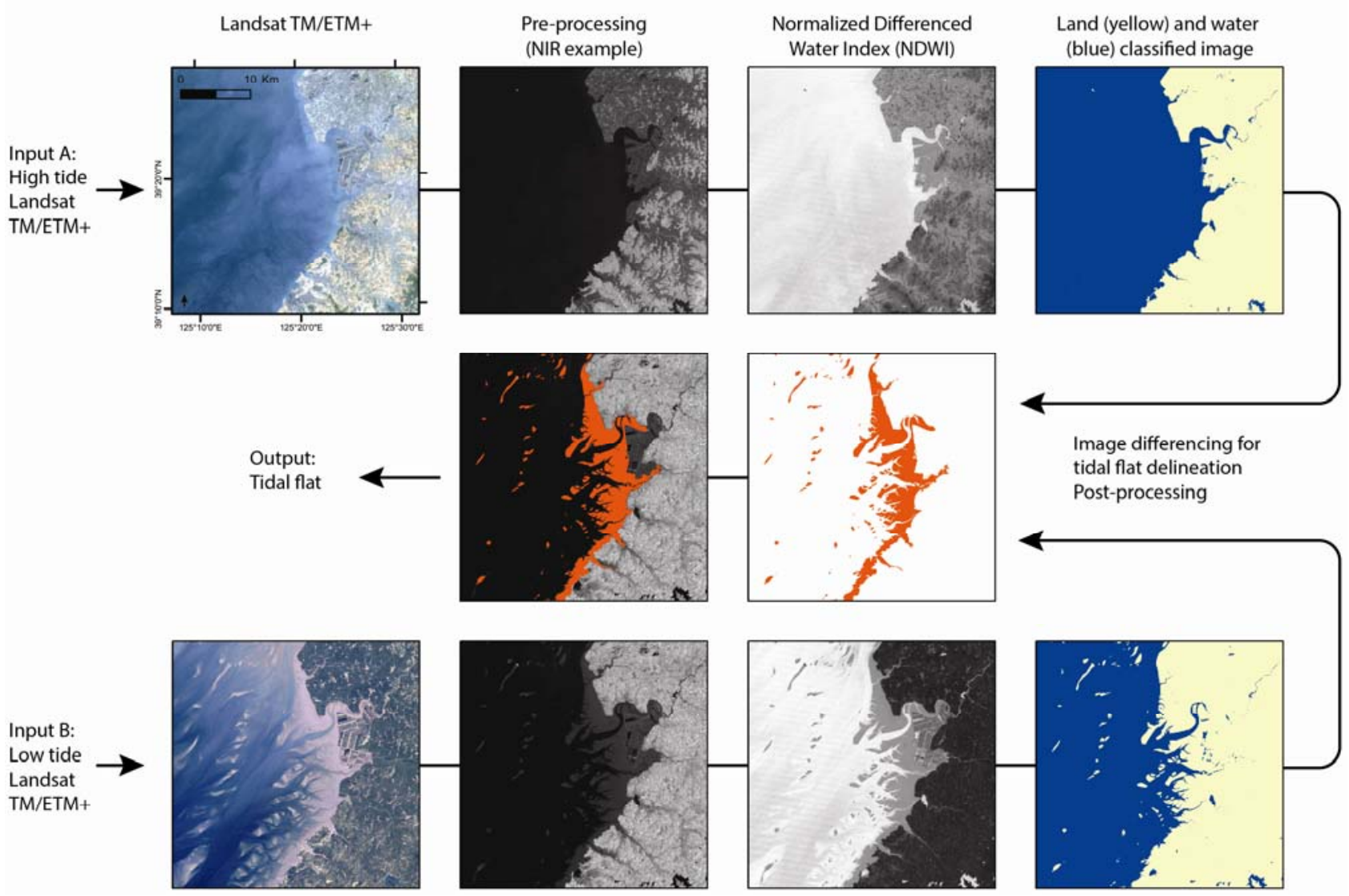


In the first phase, we generated a land and water class image using the Normalized Differenced Water Index (NDWI) [23]. The NDWI is widely used to delineate open water features from terrestrial environments [24,25] and as it includes the Near Infrared (NIR) and a visible band, is suitable for delineating the waterline in tidal habitats [12]. We calculated NDWI for each pixel with the following formula:

$$
R_{T M / E T M}=\frac{\rho_{\text {green }}-\rho_{N I R}}{\rho_{\text {green }}+\rho_{N I R}}
$$

where $\rho_{\text {green }}$ and $\rho_{N I R}$ are the radiances of the green and near infrared wavelengths [24]. As the land-water threshold of NDWI is known to vary between images in multi-temporal studies, we manually applied a threshold on an image-by-image basis, producing an image set comprising of high tide and low tide images classified into 2 classes, land and water [11,23].

In the second phase we subtracted the high tide water class from the low tide water class, enabling the area that changed between high and low tide to be identified; the tidal flat. The tidal flat output was post-processed to remove random incorrect pixels and areas that had changed between high and low tide images but were not tidal flats, such as coastal developments or flooding of aquaculture ponds. Additionally, a manually-derived mask was applied to remove areas that were (i) covered by cloud, (ii) certainly not tidal, such as land or deep ocean or (iii) areas where waterline delineation could not be achieved due to siltation, ice or algal blooms.

\subsection{Accuracy Assessment}

The accuracy measures (overall, user's and producer's) of the resulting spatial estimate of tidal flat extent were derived and assessed by independently comparing reference data with map data in a confusion matrix [26,27]. We generated 260 sample locations by stratified random sampling the non-masked area for the two output classes (tidal flat and other). Map data was extracted for these points from the tidal flat map. Reference data were derived by an independent analyst who labeled each sample point with tidal flat or other class, based on assessment all available Landsat bands of the low-tide images and other available information (such as Google Earth).

\section{Results and Discussion}

We utilized 78 Landsat TM and ETM+ images to produce the first continental scale map of tidal flats, covering 13,800 km (86.8\%) of the China, Democratic People's Republic of Korea and Republic of Korea coast (Figure 3).

Overall classification accuracy across the sample set was $89.2 \%$, with a user's accuracy of $91.1 \%$ and a producer's accuracy of $86.9 \%$ (Table 1). Such a high level of accuracy is not surprising given the manual application of the land-water threshold to each NDWI image, the use of Landsat TM/ETM+ for validation and the small number of mapping categories [11,23,27]. Misclassified pixels overwhelmingly occurred in the landward region of the tidal flat on slivers of exposed surface between the high tide waterline that we detected and the natural coastline or seawall. Such misclassifications generally arose from limited availability of spring high tide images, which required the use of images acquired below the highest possible tide, although these were always within the upper $10 \%$ of the tidal range. Despite using accurate, regionally validated tide models available there were small errors in tide 
height predictions, as well as from natural variation in tide heights across each Landsat image [16,17]. Our method results in estimates that are conservative compared with the actual tidal area, because complete delineation of the entire intertidal area can only be achieved when the images are precisely timed relative to the extremes of the tide. Nevertheless, the accuracy of our method for mapping exposed tidal flat is well within the bounds of widely accepted targets for remote sensing [27].

Figure 3. Areas of mapped coastline using the image differencing method. The inset shows an example for a coastal area of Democratic People's Republic of Korea at (a) low tide, (b) high tide and (c) the mapped tidal flat (red).

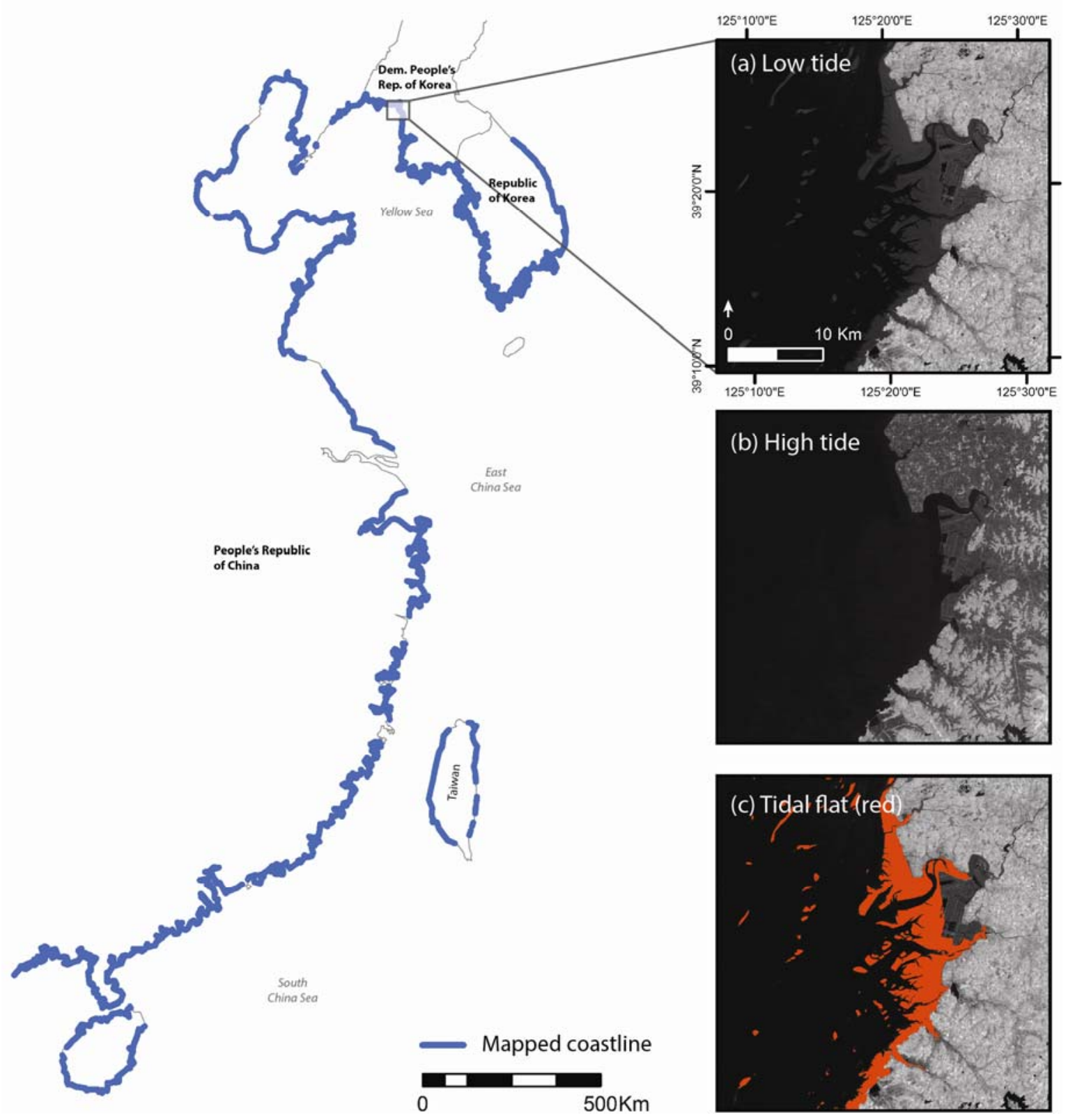

Due to environmental factors such as cloud cover, sea ice, extreme water turbidity, pollution, algal blooms and vegetation cover it was not possible to map $13.2 \%$ of the study coastline. Because paired images were required for image differencing, if one these factors occurred on either image then mapping the tidal flat was not possible for that area. Additionally, the occurrence of SLC-off striping 
on recent ETM+ imagery resulted in some striped areas of no-data within the mapped output that could not be gap-filled due to varying tide heights in other available imagery [22].

Table 1. Confusion matrix for the image differencing method for mapping tidal flat. The matrix shows the actual and classified cases in the columns and rows, respectively. The proportion of correctly allocated cases indicates the overall classification accuracy.

\begin{tabular}{|c|c|c|c|c|}
\hline \multirow{2}{*}{ Classified } & \multicolumn{2}{|c|}{ Reference } & \multirow{2}{*}{$\sum$ Producer } & \multirow{2}{*}{$\begin{array}{c}\text { Producer's } \\
\text { accuracy }(\%)\end{array}$} \\
\hline & Tidal Flat & Other & & \\
\hline Tidal flat & 113 & 17 & 130 & 86.9 \\
\hline Other & 11 & 119 & 130 & 91.5 \\
\hline$\sum$ user & 124 & 136 & 260 & \\
\hline User's accuracy (\%) & 91.1 & 87.5 & & \\
\hline \multicolumn{4}{|c|}{ Overall Accuracy (\%) } & 89.2 \\
\hline
\end{tabular}

The availability of suitable high and low tide images resulted in considerable periods of time elapsing between acquisitions of each paired image. For the coastline of China and South Korea particularly, anthropogenic coastal modification, including widespread land reclamation, is occurring at such a rapid rate that the coastline can change between image acquisitions. For example, land claims for coastal development were occasionally identified as tidal flat because they changed from water to land between the high and low tide images. Such artifacts were removed manually during post-processing. Furthermore, the dynamic nature of tidal flats, particularly in estuaries where accretion and erosion continually occur as well as areas with regular seasonal changes of tidal flat extent, can lead to changes in the tidal flat extent between the acquisitions of suitable images.

Ryu et al. [13] investigated the accuracy of several approaches for delineating tidal flats based on waterline delineation and showed that although some methods can result in error of up to several hundred meters, best performance was achieved using a combination of the NIR and a visible band, preferably on a flood tide when the exposed sediment is most dry. By using the NDWI, which includes the NIR and the green band, we adopted a high performing, widely accepted method for delineating open water features [24]. However, evaluation of waterline mapping on tidal flats with the NDWI is required, preferably with on-ground reference data collected at known tide stages and heights at the same time as sensor data. Since the threshold value of the NDWI for delineating open water features is known to vary among scenes with TM or ETM+ data $[23,28]$, additional work to predict the waterline threshold using individual image properties would allow for further automation of our methodology [23].

Tidal flats are declining in area in many regions due to human impacts and sea-level rise, leading to suspected declines in biodiversity [29,30], loss of ecosystem services [2,31] and negative impacts to human livelihoods $[2,6]$. As such, an analysis of their current status is urgently required. Our method could be applied to all images in the Landsat Archive (MSS, TM or ETM+), which will allow the status of tidal flats to be determined for any region where sufficient Landsat data exist. Additionally, the method is suitable for application to other sensor data, permitting the use of a wide range of sensors to meet varying objectives. For example, if higher resolution mapping of the tidal area is sought, perhaps for areas with very small tidal flats, obtaining data at the relevant tides from a high resolution source such as Quickbird, Worldview 2, IKONOS or SPOT would be possible. Likewise, if the aim is to determine the maximum area of tidal flat, then the use of a high repeat frequency sensor 
such as MODIS would likely increase the likelihood of obtaining images acquired on the highest and lowest tide, although its resolution would restrict its application to large tidal flats only.

\section{Conclusions}

Despite major advances in applications of remote sensing, such as the suite of global land-cover maps and habitat specific atlases, the spatial distribution and status of intertidal habitats globally remains poorly understood. Here we present a simple, broadly applicable method developed for mapping tidal flats over large areas (continental to global) using the Landsat archive of TM and ETM+ imagery. We used regional tide models to select Landsat images that were captured only at high or low tide. These images were pre-processed and classified into land and water classes using the Normalized Differenced Water Index (NDWI). Differencing of the high and low tide NDWI images allowed delineation of the tidal flat.

To demonstrate the method, we produced the first map of tidal flats of China and the Korean peninsula, an area that is undergoing rapid coastal change and is at-risk from coastal inundation due to sea level rise. We used 78 Landsat TM and ETM+ images to map tidal flats over 13,800 km of coastline. The accuracy assessment indicated an overall classification accuracy of $89.2 \%$. Tidal flats in the region are threatened by intense coastal development, and our map will provide a baseline that allows for the monitoring of future impacts to tidal flats.

Importantly, the method can be rapidly and efficiently applied to all Landsat imagery in the Landsat Archive, allowing the status of tidal flats to be determined for any region around the world. This will prove a useful tool for studies of ecological and morphological change in coastal regions, particularly with regard to ecosystem services, climate adaptation responses, biodiversity conservation, human impacts and coastal management. Future implementation of this method will focus on obtaining wider geographic coverage of tidal flat maps, with the aim to eventually understand the status of tidal flats globally.

\section{Acknowledgments}

This work was supported by Linkage Grant LP100200418 from the Australian Research Council, co-funded by the Queensland Department of Environment and Resource Management, the federal Department of Sustainability, Environment, Water, Population and Communities, the Queensland Wader Study Group and the Port of Brisbane Pty Ltd. Additional support came from a Birds Queensland Research Grant and a CSIRO Climate Adaptation Flagship scholarship (to N.J.M.). We thank Mitchell Lyons, Jeffrey Hanson and Vladimir Wingate for advice, programming support and assistance with the accuracy assessment. We also thank Tony Gill and Lisa Hardy (Joint Remote Sensing Research Program/Remote Sensing Centre at Queensland Department of Science, Information Technology Innovation and the Arts) for Landsat Archive processing expertise and early discussions.

\section{References and Notes}

1. Healy, T.; Wang, Y.; Healy, J.-A. Muddy Coasts of the World: Processes, Deposits, and Function; Elsevier Science: Amsterdam, The Netherlands, 2002. 
2. Millennium Ecosystem Assessment Board. Ecosystems and Human Well-Being: Current State and Trends, 1st ed.; Island Press: Washington, DC, USA, 2005.

3. Cracknell, A.P. Remote sensing techniques in estuaries and coastal zones-An update. Int. J. Remote Sens. 1999, 20, 485-496.

4. Green, E.P.; Mumby, P.J.; Edwards, A.J.; Clark, C.D. A review of remote sensing for the assessment and management of tropical coastal resources. Coast. Manage. 1996, 24, 1-40.

5. Phinn, S.R.; Menges, C.; Hill, G.J.E.; Stanford, M. Optimizing remotely sensed solutions for monitoring, modeling, and managing coastal environments. Remote Sens. Environ. 2000, 73, 117-132.

6. MacKinnon, J.; Verkuil, Y.I.; Murray, N.J. IUCN Situation Analysis on East and Southeast Asian Intertidal Habitats, with Particular Reference to the Yellow Sea (including the Bohai Sea); IUCN: Gland, Switzerland / Cambridge, UK, 2012.

7. Syvitski, J.P.M.; Kettner, A.J.; Overeem, I.; Hutton, E.W.H.; Hannon, M.T.; Brakenridge, G.R.; Day, J.; Vorosmarty, C.; Saito, Y.; Giosan, L.; et al. Sinking deltas due to human activities. Nature Geosci. 2009, 2, 681-686.

8. Gade, M.; Alpers, W.; Melsheimer, C.; Tanck, G. Classification of sediments on exposed tidal flats in the german bight using multi-frequency radar data. Remote Sens. Environ. 2008, 112, $1603-1613$.

9. Ryu, J.H.; Kim, C.H.; Lee, Y.K.; Won, J.S.; Chun, S.S.; Lee, S. Detecting the intertidal morphologic change using satellite data. Estuar. Coast. Shelf Sci. 2008, 78, 623-632.

10. Chen, L.C. Detection of shoreline changes for tideland areas using multi-temporal satellite images. Int. J. Remote Sens. 1998, 19, 3383-3397.

11. Zhao, B.; Guo, H.; Yan, Y.; Wang, Q.; Li, B. A simple waterline approach for tidelands using multi-temporal satellite images: A case study in the Yangtze delta. Estuar. Coast. Shelf Sci. 2008, 77, 134-142.

12. White, K.; El Asmar, H.M. Monitoring changing position of coastlines using Thematic Mapper imagery, an example from the Nile delta. Geomorphology 1999, 29, 93-105.

13. Ryu, J.H.; Won, J.S.; Min, K.D. Waterline extraction from Landsat TM data in a tidal flat-A case study in Gomso Bay, Korea. Remote Sens. Environ. 2002, 83, 442-456.

14. Foody, G.M.; Muslim, A.M.; Atkinson, P.M. Super-resolution mapping of the waterline from remotely sensed data. Int. J. Remote Sens. 2005, 26, 5381-5392.

15. U.S. Geological Survey. Earth Explorer; Available online: http://earthexplorer.usgs.gov (accessed on 21 February 2011).

16. Zu, T.; Gan, J.; Erofeeva, S.Y. Numerical study of the tide and tidal dynamics in the South China Sea. Deep-Sea Res. I 2008, 55, 137-154.

17. Egbert, G.D.; Erofeeva, S.Y. Efficient inverse modeling of barotropic ocean tides. J. Atmos. Ocean. Tech. 2002, 19, 183-204.

18. Erofeeva, S.Y.; Padman, L. The Tide Model Driver Version 2.02; Available online: http://www.esr.org/ptm_index.html (accessed on 22 March 2011).

19. Chander, G.; Markham, B.L.; Helder, D.L. Summary of current radiometric calibration coefficients for Landsat MSS, TM, ETM+, and EO-1 ALI sensors. Remote Sens. Environ. 2009, 113, 893-903. 
20. Chavez, P.S. An improved dark-object subtraction technique for atmospheric scattering correction of multispectral data. Remote Sens. Environ. 1988, 24, 459-479.

21. Song, C.; Woodcock, C.E.; Seto, K.C.; Lenney, M.P.; Macomber, S.A. Classification and change detection using Landsat TM data: When and how to correct atmospheric effects? Remote Sens. Environ. 2001, 75, 230-244.

22. Irish, R. Landsat 7 Science Data Users Handbook; Landsat Project Science Office-NASA's Goddard Space Flight Center: Greenbelt, MD, USA, 2008.

23. Liu, Y.; Song, P.; Peng, J.; Ye, C. A physical explanation of the variation in threshold for delineating terrestrial water surfaces from multi-temporal images: Effects of radiometric correction. Int. J. Remote Sens. 2012, 33, 5862-5875.

24. McFeeters, S.K. The use of the Normalized Difference Water Index (NDWI) in the delineation of open water features. Int. J. Remote Sens. 1996, 17, 1425-1432.

25. Ouma, Y.O.; Tateishi, R. A water index for rapid mapping of shoreline changes of five East African rift valley lakes: An empirical analysis using Landsat TM and ETM+ data. Int. J. Remote Sens. 2006, 27, 3153-3181.

26. Foody, G.M. Sample size determination for image classification accuracy assessment and comparison. Int. J. Remote Sens. 2009, 30, 5273-5291.

27. Congalton, R.G. Assessing the accuracy of remotely sensed data: Principles and practices. CRC Press: London, UK, 1999.

28. $\mathrm{Xu}, \mathrm{H}$. Modification of Normalised Difference Water Index (NDWI) to enhance open water features in remotely sensed imagery. Int. J. Remote Sens. 2006, 27, 3025-3033.

29. Szabo, J.K.; Butchart, S.H.M.; Possingham, H.P.; Garnett, S.T. Adapting global biodiversity indicators to the national scale: A Red List index for Australian birds. Biol. Conserv. 2012, 148, $61-68$.

30. Wilson, H.B.; Kendall, B.E.; Fuller, R.A.; Milton, D.A.; Possingham, H.P. Analyzing variability and the rate of decline of migratory shorebirds in Moreton Bay, Australia. Conserv. Biol. 2011, 25, 758-766.

31. An, S.Q.; Li, H.B.; Guan, B.H.; Zhou, C.F.; Wang, Z.S.; Deng, Z.F.; Zhi, Y.B.; Liu, Y.H.; Xu, C.; Fang, S.B.; et al. China's natural wetlands: Past problems, current status, and future challenges. Ambio 2007, 36, 335-342.

(C) 2012 by the authors; licensee MDPI, Basel, Switzerland. This article is an open access article distributed under the terms and conditions of the Creative Commons Attribution license (http://creativecommons.org/licenses/by/3.0/). 